inflamatoria pélvica, dada la edad de la paciente y que presentaba factores de riesgo como la utilización de DIU. También se puede realizar una RM potenciada en T2 sin contraste $^{6}$ o una RM urográfica tras la administración de contraste i.v. en la fase excretora.

En un estudio Kim $\mathrm{YJ}^{7}$ concluye que es necesario el seguimiento a largo plazo del uréter remanente, ya que en 318 pacientes nefrectomizados por patología benigna diagnosticó 8 tumores, 6 de ellos con antecedentes de pionefrosis y 2 de tuberculosis renal (resultado anatomopatológico de 6 carcinomas de células transicionales y 2 escamosos) y con un periodo medio libre de enfermedad de 76,5 meses. En 1994 Fariña L.A. aportó 2 casos de aparición de neoplasia en el muñón ureteral, uno de ellos 38 años después de una nefrectomía por tuberculosis renal ${ }^{8}$.

El tratamiento definitivo de esta patología es la escisión del uréter remanente. En nuestro caso se realizó en un primer tiempo tratamiento mediante drenaje de la colección, quedando pendiente la realización de la ureterectomía.

B I B L I O G R A F Í A

1. Ikeda D, Matsutani R, Fukuda M, Fuse H, Hirano S. Transurethral fulguration for empyema of ectopic ureteral stump. Int J Urol. 2003;10:664-6.

2. Pollack HM, Banner MP, Popky GL. Radiologic evaluation of the ureteral stump. Radiology. 1982;144:225-30.
3. Prajsner A, Szewczyk W, Gawron R. Empyema of retained ureteral stump with gross stone 20 years after nephrectomy. Urology. 2009;73:993-4.

4. Barroso Jr U, Calado AA, Filho MZ. The role of refluxing distal ureteral stumps after nephrectomy. J Pediatr Surg. 2002;37:653-6.

5. Persad R, Kamineni S, Mouriquand PD. Recurrent symptoms of urinary tract infection in eight patients with refluxing ureteric stumps. Br J Urol. 1994;74:720-2.

6. Leyendecker JR, Barnes CE, Zagoria RJ. MR urography: techniques and clinical applications. Radiographics. 2008;28:23-46. discussion 46-7.

7. Kim YJ, Jeon SH, Huh JS, Chang SG. Long-term follow-up of ureteral stump tumors after nephrectomy for benign renal disease. Eur Urol. 2004;46:748-52.

8. Fariña LA, Caparros Sariol J, Villavicencio Mavrich H. Carcinoma of the residual ureter many years after nephrectomy: an evasive cause of hematuria and a high risk tumor. Arch Esp Urol. 1994;47:581-4.

L. Labairu-Huerta ${ }^{a}, *$ A. Burguete-Moriones ${ }^{b}$,

J. Zabalza-Unzuéb y V. Grasa-Lanau ${ }^{\mathrm{a}}$

${ }^{a}$ Servicios de Urología, Hospital de Navarra, Pamplona, España

${ }^{\mathrm{b}}$ Servicios de Radiodiagnóstico, Hospital de Navarra, Pamplona, España

*Autor para correspondencia.

Correo electrónico: luislabairu@hotmail.com

(L. Labairu-Huerta).

\title{
Metástasis en la vagina como primer síntoma de un carcinoma de células renales
}

\section{Vaginal metastasis as the first sign of renal cell carcinoma}

\section{Sr. Director:}

El carcinoma de células renales (CCR) tiene frecuentemente un curso clínico impredecible, y aunque son frecuentes las metástasis a distancia en el momento del diagnóstico, incluso como forma de presentación del tumor, son excepcionales en la vagina y hay menos de 100 casos descritos, según la literatura médica revisada ${ }^{1-10}$.

Presentamos un caso correspondiente a una mujer de 53 años, sin antecedentes de interés, que consultó por sangrado vaginal. En la exploración ginecológica se observó una tumoración polipoide, necrosada, de aspecto infiltrativo en la cara anterior y en el fondo del saco derecho de la vagina que se biopsió. Histológicamente, fue diagnosticado de carcinoma de células claras (CCC) muy sugestivo de origen renal (queratina, vimentina, EMA, CD10 y anticuerpo para CCR positivo) (fig. 1), por lo que se recomendó valorar clínica y radiológicamente esta posibilidad. La tomografía computarizada abdominopelviana demostró un tumor renal de $12 \mathrm{~cm}$ de diámetro máximo que ocupaba el tercio medio y superior del riñón derecho, invadía el seno renal (fig. 2) y mostraba importante circulación colateral, sobre todo venosa (fig. 2, flecha), que se dirigía a través de la vena ovárica derecha hacia la pelvis (fig. 2, *). No se observó patología a ningún otro nivel y la gammagrafía ósea fue negativa. No se realizó nefrectomía por la rápida progresión de la metástasis vaginal y la paciente recibió radioterapia pelviana con finalidad hemostática. A los 10 meses del diagnóstico inicial y después de recibir tratamiento con radioterapia, la paciente presentó progresión de la enfermedad con aumento de 


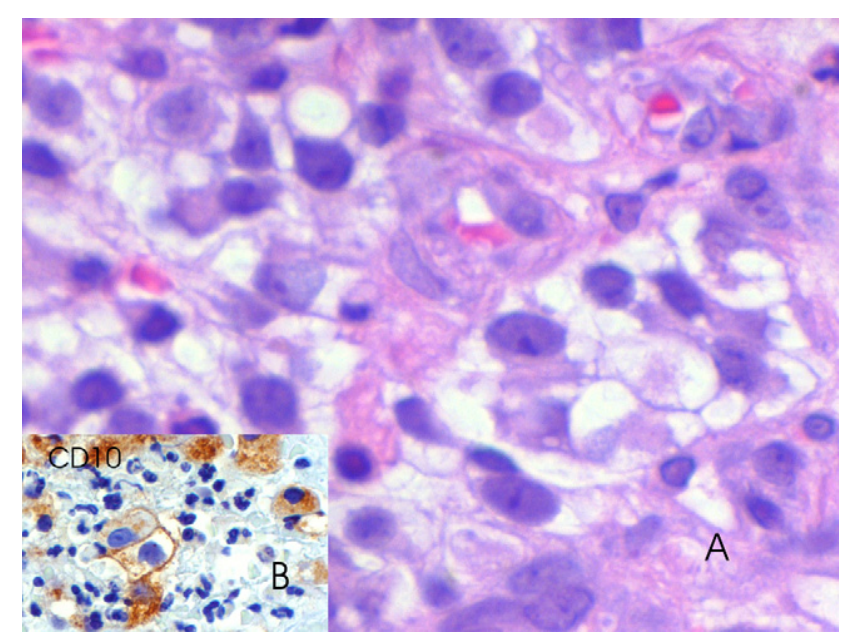

Figura 1 - Carcinoma de células claras. A) Hematoxilinaeosina. B) CD10.

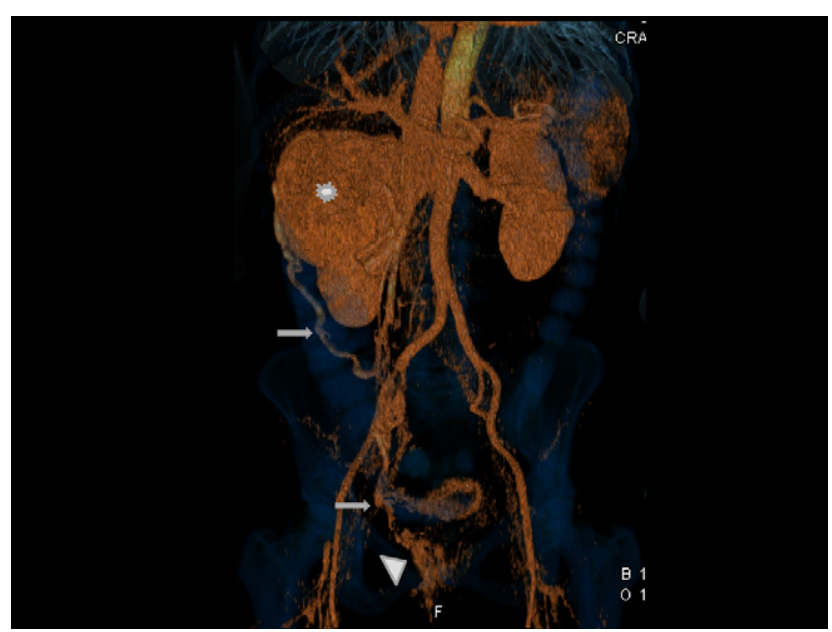

Figura 2 - Tomografía computarizada de abdomen y pelvis que muestra una masa del riñón derecho con importante circulación colateral.

tamaño de la lesión vaginal y aparición de metástasis pulmonares.

El CCR presenta metástasis en el $20 \%$ de los casos en el momento del diagnóstico. Las metástasis más habituales de este tumor son en los pulmones, los huesos, el hígado, la glándula suprarrenal y el sistema nervioso central, siendo excepcionales las metástasis en la vagina.

Los adenocarcinomas de vagina son infrecuentes y casi siempre metastásicos. En mujeres jóvenes, los CCC primarios de vagina suelen estar asociados a la exposición intraútero de dietilestilbestrol. En mujeres mayores son casi siempre metastásicos y, a veces, como es nuestro caso, es la forma de presentación. Los adenocarcinomas metástasicos en la vagina suelen ser de origen ginecológico y de colon (el 65\% de los casos) y solo excepcionalmente son de origen renal. El diagnóstico de metástasis de CCR a la vagina no se suele sospechar clínicamente, en algunas ocasiones por el largo intervalo de tiempo desde la nefrectomía hasta la aparición de la lesión ${ }^{8}$ y más frecuentemente por ser la forma de presentación de la neoplasia ${ }^{4}$. Histológicamente, hay que descartar el origen renal en todos los CCC, sea cual sea su localización, ya que los tumores renales se caracterizan por tener una evolución impredecible y por metastatizar en localizaciones poco usuales. Para descartar el origen primario de la neoplasia, hay que recurrir a las técnicas de inmunohistoquímica. La positividad para el CD10 y EMA nos confirma el origen renal y descarta el origen ginecológico e intestinal. Sin embargo, la sensibilidad y la especificidad de estos marcadores son bajas y se pueden expresar también en otros tumores ${ }^{9}$. Actualmente, se está empleando un antígeno del CCR que, aunque no es absolutamente específico, presenta una alta sensibilidad para detectar CCR, especialmente cuando se emplea junto a los otros marcadores comentados anteriormente ${ }^{9}$. Nuestro caso fue positivo para el CD10 y EMA, confirmando el origen renal de la lesión, aunque no tenía ninguna sintomatología ni sospecha clínica. $\mathrm{El}$ antígeno de CCR fue negativo en nuestro caso.

Las metástasis en la vagina son más frecuentes en los tumores localizados en el riñón izquierdo y el modo de diseminación parece ser a través de la extensión venosa retrógrada ${ }^{10}$. En nuestro caso, el tumor se localizó en el riñón derecho y se observó una importante circulación colateral venosa alrededor de la neoplasia, que se dirigía a través de la vena ovárica derecha hacia la pelvis, observándose el desarrollo de una importante circulación parauterina, pero no se observó afectación de la vena, la arteria renal ni de la vena cava subinferior. Estos datos sugieren que pueden existir vías vasculares alternativas para la diseminación de la neoplasia.

B I B L I O G R A F Í A

1. Sharma ND, McKelvie GB. Genital tract metastasis from renal cell carcinoma - a case report and discussion. Scott Med J. 1985;30:43-5.

2. Bouyounes BT, bihrte III W. Renal cell carcinoma presenting as vaginal bleeding. J Urol. 1998;160:1797.

3. Terraza Jr HM, Meltzer SE, De Cain M, Jones MA. Vaginal metastases from renal cell carcinoma: Report of four cases and review of the literature. Eur J Gynaecol Oncol. 1998;19:11-4.

4. Abraham R, Thomas DR, Foster MC. Vaginal bleeding as a presentation of metastatic renal cell carcinoma. BJU Int. 1999;84:384-5.

5. Queiroz C, Bacchi CE, Oliveira C, Carvalho M, Santos DR. Cytologic diagnosis of vaginal metastasis from renal cell carcinoma. A case report. Acta Cytol. 1999;43:1098-100.

6. Wyezolkwski M, Klima W, Bieda W, Walas K. Spontaneous regression of hepatic metastases after nephrectomy and metastasectomy of renal cell carcinoma. Urol Int. 2001;66: 119-20.

7. Allard JE, McBroom JW, Zahn CM, McLeod D, Maxwell GL. Vaginal metastasis and thrombocytopenia from renal cell carcinoma. Gynecol Oncol. 2004;92:970-3.

8. Pruthi RS, Richman M, Derksen JE, Maygarden S. Stage T1 renal carcinoma relapsing in the vagina 10 years after initial diagnosis. J Urol. 2003;170:2379-80.

9. Bakshi N, Kunju LP, Giordano T, Shah RB. Expression of renal cell carcinoma antigen (RCC) in renal epithelial and nonrenal tumors. Diagnostic implications. Appl Immunohistochem Mol Morphol. 2007;15:310-5. 
10. Mulcahy JJ, Furlow WL. Vaginal metastasis from renal cell carcinoma: Radiographic evidence of possible route of spread. J Urol. 1970;104:50-2.

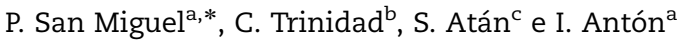

${ }^{a}$ Servicio de Anatomía Patológica, Hospital Povisa, Vigo,

Pontevedra, España
${ }^{\mathrm{b}}$ Servicio de Rayos, Hospital Povisa, Vigo, Pontevedra, España

'Servicio de Ginecología, Hospital Povisa, Vigo, Pontevedra, España

*Autor para correspondencia.

Correo electrónico: psanmiguel@povisa.es (P. San Miguel).

\section{Graves consecuencias del tratamiento mediante esclerosis con ácido acético en un caso de linfangioma quístico retroperitoneal}

\section{Serious consequences of the treatment by sclerotherapy with acetic acid in a case of retroperitoneal cystic lymphangioma}

\section{Sr. Director:}

Los tumores retroperitoneales constituyen un conjunto de neoplasias poco frecuentes derivadas de los vasos, los nervios, el tejido muscular y los restos embrionarios ${ }^{1}$. Entre los distintos tipos encontramos el linfangioma quístico retroperitoneal. Este es un tumor benigno y con escasa incidencia, cuyo origen radica en una alteración del desarrollo del sistema linfático².

Presentamos un caso de linfangioma quístico retroperitoneal tratado con ácido acético y con el resultado de necrosis de la pared del colon derecho y graves complicaciones posteriores.

Varón de 45 años con antecedentes personales de dislipemia, litiasis renal e intervenido hace 30 años de linfangioma quístico retroperitoneal a través de laparotomía (no aporta informes) que consulta en el servicio de digestivo por dolor en la zona lumbar derecha de tres meses de duración irradiado a flanco derecho las últimas semanas sin otra sintomatología acompañante. En la exploración se palpa una masa en el hemiabdomen derecho. Se procede así a realizar una tomografía axial computarizada (TAC) abdominopélvico (fig. 1), donde se evidencia una voluminosa masa quística polilobulada retroperitoneal en el hemiabdomen derecho compatible con linfangioma macroquístico retroperitoneal; la masa rodea y desplaza el riñón derecho, el colon ascendente, la cabeza del páncreas, la $2 .^{\mathrm{a}}$ y la $3 .^{\mathrm{a}}$ porción duodenal, la cava inferior, la aorta y los vasos ilíacos. Debido a la relación tan estrecha del linfangioma con estructuras vitales se rechaza la cirugía.

Se procede así a la inyección de ácido acético como tratamiento alternativo. Bajo control de la TAC se drena el quiste, obteniéndose $1.300 \mathrm{~cm}^{3}$ de líquido lechoso. Una vez descartadas las comunicaciones anómalas con el resto del retroperitoneo (al inyectar contraste yodado), se esclerosa con $100 \mathrm{~cm}^{3}$ de ácido acético al $40 \%$ y tras 20 min se extrae y se lava abundantemente con suero, dejando un drenaje.

Durante los días posteriores, el paciente presenta dolor abdominal controlado con analgesia y hematuria autolimitada las primeras $24 \mathrm{~h}$, que se atribuye a inflamación ureteral. Cuatro días después se realiza una TAC de control, en la cual se objetiva una esclerosis casi total de linfangioma (pequeño lóculo residual de $2 \times 1 \mathrm{~cm}$ ), por lo que se retira el drenaje.

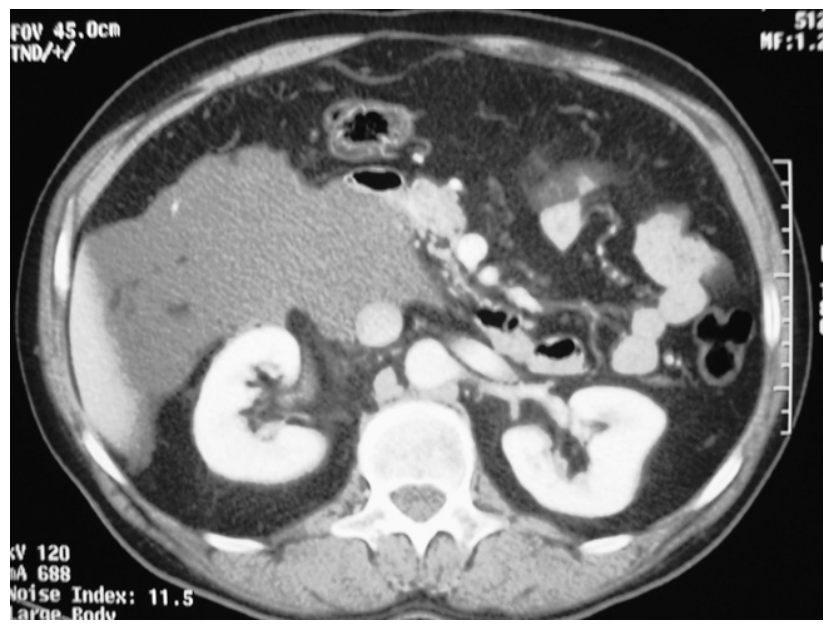

Figura 1 - Tomografía axial computarizada abdominopélvica con contraste oral e intravenoso. Se visualiza una voluminosa masa quística polilobulada retroperitoneal en el hemiabdomen derecho que rodea y desplaza el riñón derecho, el colon ascendente, la cabeza del páncreas, la $2 .^{a}$ y la 3. ${ }^{a}$ porción duodenal, la cava inferior, la aorta y los vasos ilíacos. 